\title{
Pedestrian Pedagogy: The Walking Library for Women Walking
}

Dee Heddon ${ }^{1}$ and Misha Myers ${ }^{2}$

${ }^{1}$ University of Glasgow, Glasgow, Scotland and ${ }^{2}$ Deakin University, Melbourne, Australia 
The Walking Library for Women Walking (2016-18) is an edition of the ongoing creative research project, The Walking Library. Co-created and launched in 2012 by Dee Heddon and Misha Myers, The Walking Library explores the multiple relationships between walking, literature, and environment (see Heddon \& Myers 2014, 2017, in press).

For each edition of The Walking Library, we invite donations and suggestions of books to accompany what we propose is a pedestrian pedagogy: a learning that takes place on foot and on the move in the company of others (present and virtual), sharing and creating knowledge side-by-side, step-by-step and without hierarchy. Pedestrian pedagogy facilitates meaning-making as emergent and re-orientating (Osberg et al., 2008). In this pedestrian pedagogy learning is improvisatory and relational, engendered through the collaborative and collective body of walkers moving through space and time, side by side, in the company of each other and a diverse collection of books.

We designed The Walking Library for Women Walking (WLfWW) specifically and strategically to take (its) place against a background of walking art discourse in which women remain largely invisible. As with all editions of The Walking Library, the WLfWW started with a question to prompt suggestions of books. We asked: "What book would you recommend to a woman going for a walk; a book that might provide excellent company, inspiration, solace, advice, humour, information?"

The WLFWW received 119 donations, most of them about women and by women. People were invited to browse our library and select a book to carry on our free public walks. By performatively inscribing and re-inscribing women's historical and contemporary practices of walking, we aimed to enact an intervention into epistemologies of walking. The WLAWW was part of the Walking Women festival staged in London and Edinburgh (2016), a groundbreaking national gathering of women walking artists curated by Clare Qualmann and Amy Sharrocks. The library was also walked in Bristol, Glasgow and Newcastle, and installed in the exhibition The House that Heals the Soul (Centre for Contemporary Art, Glasgow) from 22 July - 3 September 2017. A temporary WLfWW was created for 'Moving Out of Door', an event held in Geelong, Australia, in November 2017.

Each of the $W L f W W$ walks retraced suffragette marches and actions, and expressed-as the suffragettes did before us-women's right to take up and create public space through their collective power, physical presence, and determined voices. We invited those walking with us to stop and share extracts from the books they carried, wherever they felt resonance or dissonance. As we walked together in groups ranging from 15 to 30 in number, we talked, read, attended, shared and wondered: look at that, listen to this, why is that? Stories from books - including artists books, memoirs and letters, novels, scholarly textbooks, and poetry collections - merged with the stories from our lives, a horizontal plane bridging past and futures. If The Walking Library is positioned generally as a pedestrian pedagogy, for the $W L f W W$ we sought to surface the feminist features of this mobile classroom, including the redefinition of pedagogical power and authority and "valuing personal experience, diversity and subjectivity, reconceptualising classrooms as spaces for social justice, and using learning to help students [participants] to become activists and go beyond the classroom to effect the necessary wider changes that are needed" (Geraldine McCusker, 2017, p. 448).

This photo essay includes a selection of images from the walks, of participants' walking and reading together, of their subsequent suggestions for books to include in the library written on book cards, and of their reflective writings and drawings generated in response to the walks. 


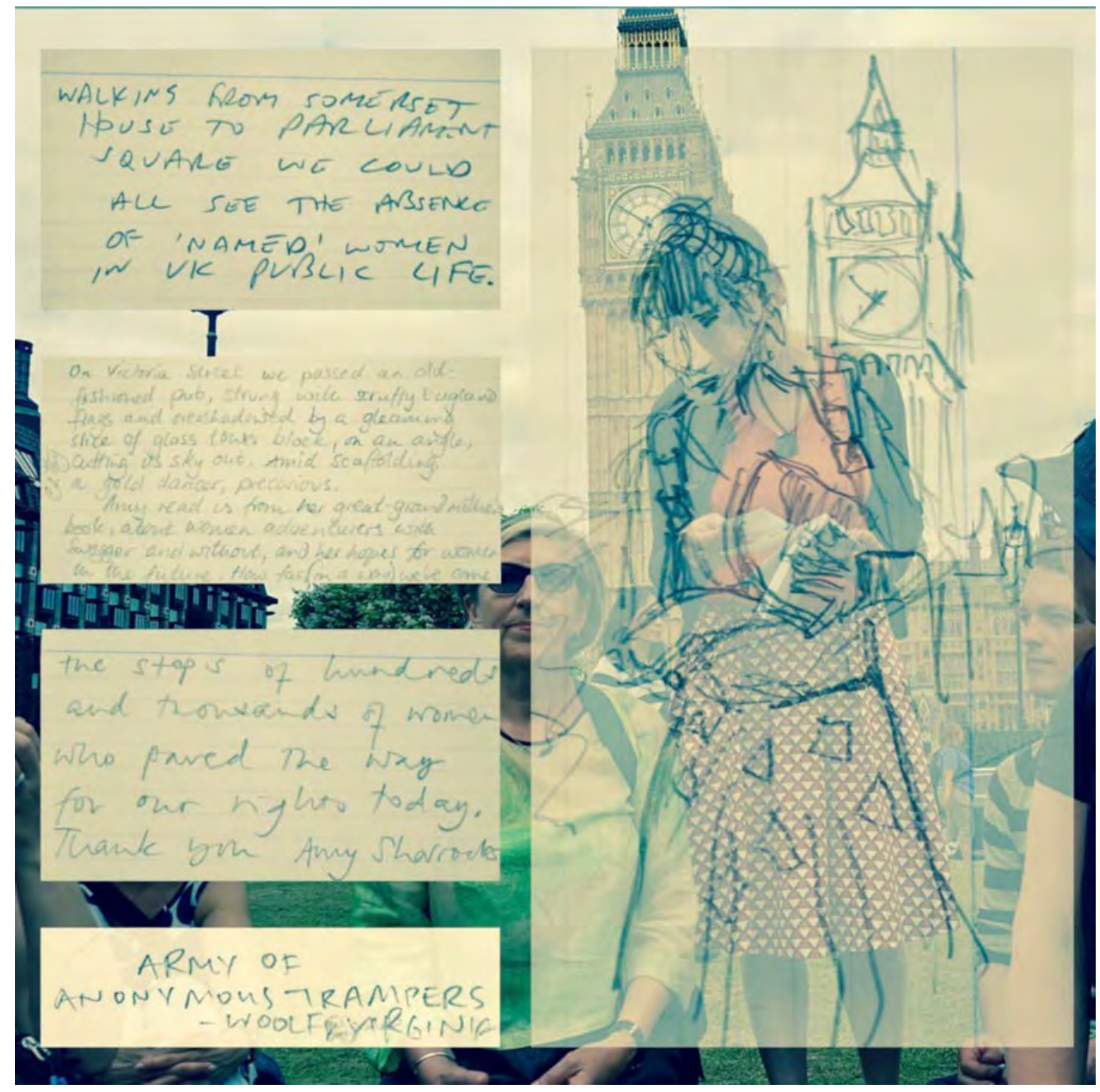

Figure 1: Composite of response cards from the Walking Library for Women Walking, two walks from Somerset House, London (UK), 16-17 July 2016, as part of Walking Women festival. We followed in the footsteps of suffragettes who marched from Embankment to Hyde Park, passing Parliament Square and stopping wherever we felt a place called to a particular book or where we encountered monuments to women (the latter turned out to be very rare). Photo credit: Photo: (c) Dee Heddon and Misha Myers, Walking Library for a Walking Women, 2016, Performance. Page design: Misha Myers. 


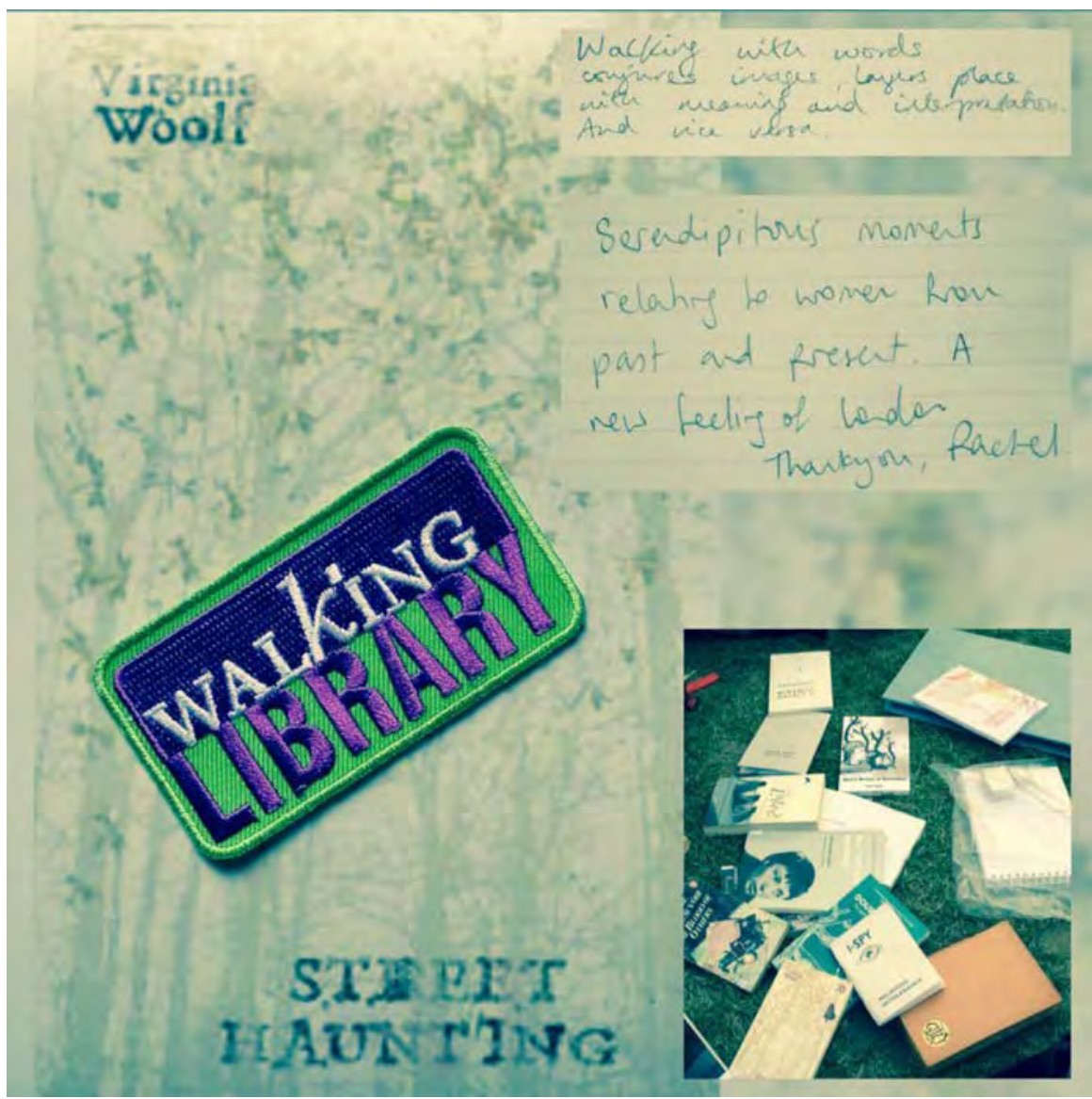

Figure 2: Image of books carried in the 'street hauntings' of the Walking Library for Women Walking, participant response cards and the Walking Library patch made especially for the Women Walking edition in the Suffragette colours of purple and green.

Photo credit: Photo: Jo Norcup of Dee Heddon and Misha Myers, Walking Library for a Walking Women, 2016, Performance. Page design: Misha Myers.

Figure 3: Composite of response cards and image of participants from the Walking Library for Women Walking, a walk along Leith Walk, Edinburgh, 11 August 2016, as part of Walking Women festival and Forest Fringe. With no suffragette path to follow, we stopped wherever we felt synergy between place and book and, instead of looking out for monuments of/to women, looked out for places where women seemed to be present. Photo credit: Photo: (c) Dee Heddon and Misha Myers, Walking Library for a Walking Women, 2016, Performance. Page design: Misha Myers.
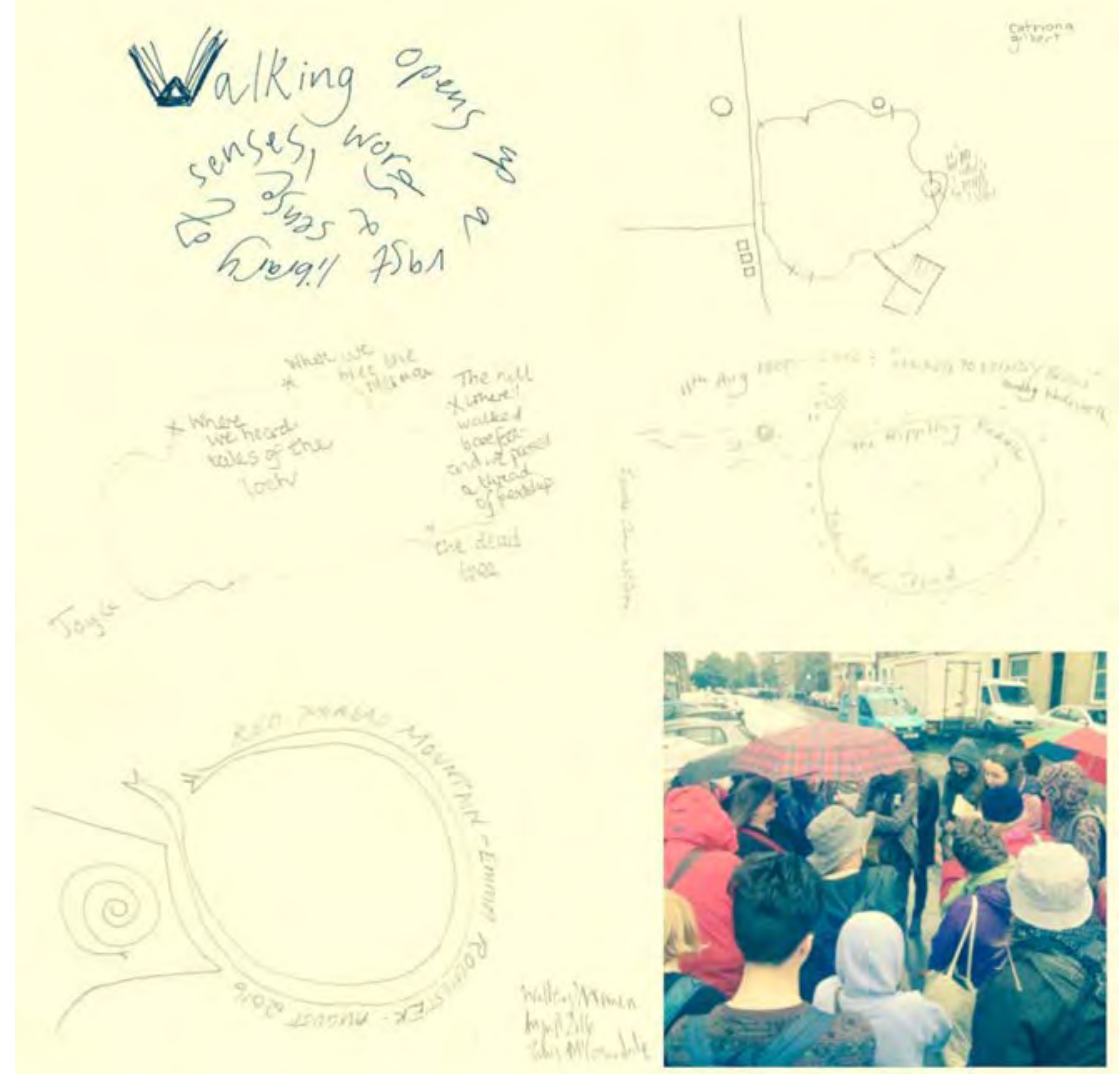


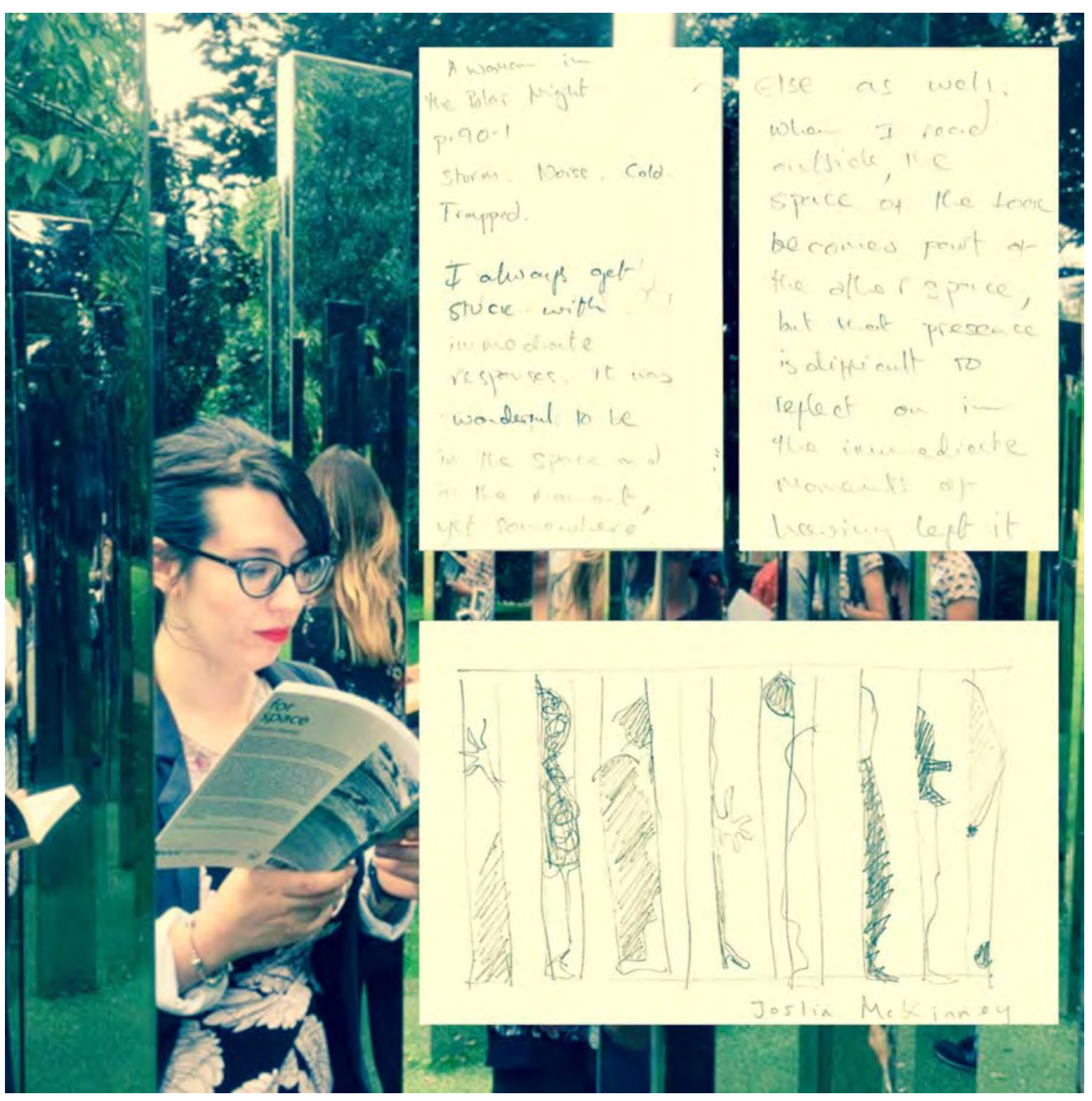

Figure 4: Composite of images of participants and their response cards from the Walking Library for Women Walking, a walk in Bristol (UK) as part of Theatre and Performance Research Association, 7 September 2016, again looking for resonances and reflections between place, book and women's presence. Photo credit: Photo: (c Dee Heddon and Misha Myers, Walking Library for a Walking Women, 2016, Performance. Page design: Misha Myers. 


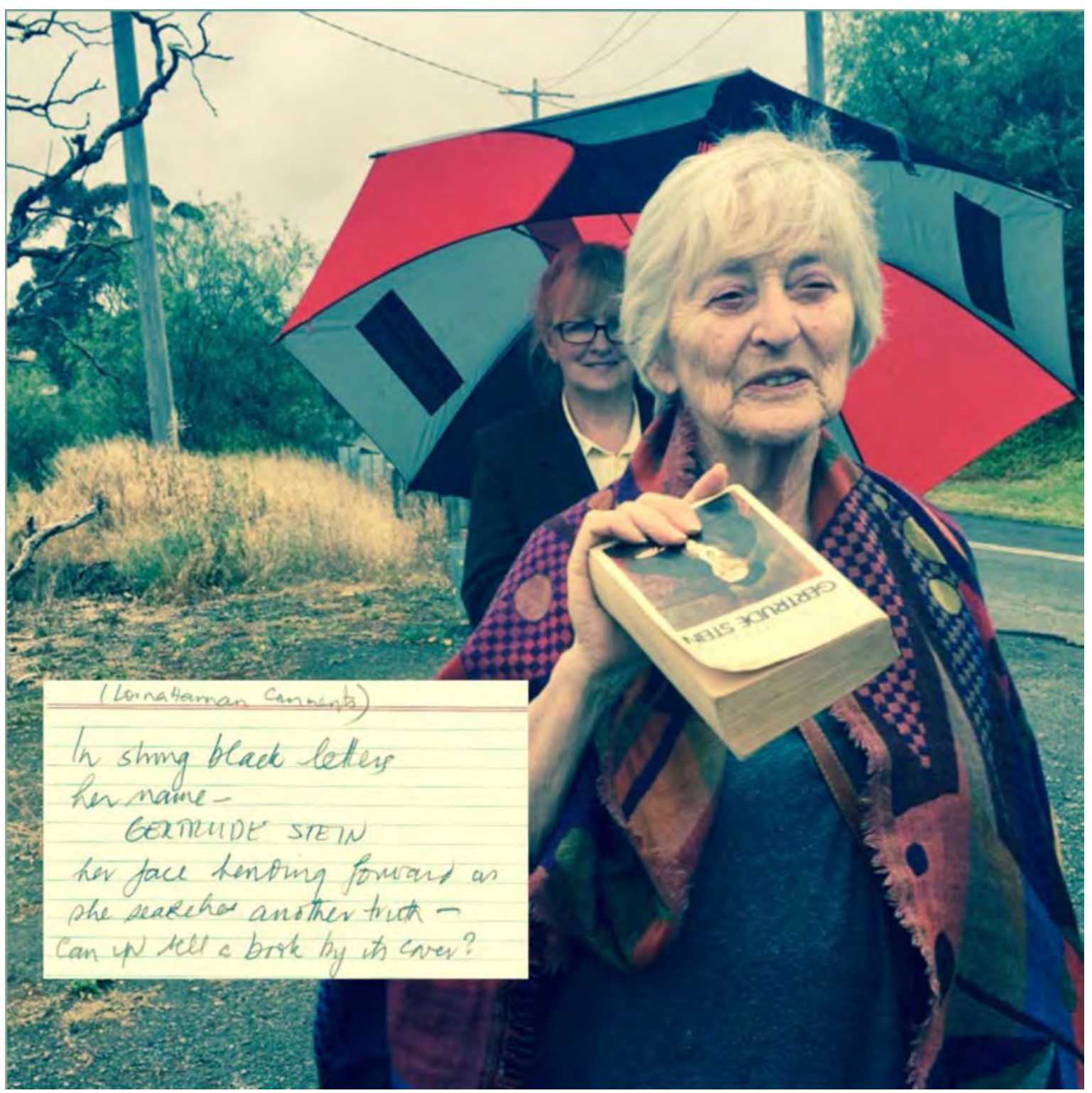

Figure 5: Image of a participant sharing the collection of Gertrude Stein's writing that she carried on the Walking Library for Women Walking walk in Geelong (Australia), 16 November 2017 from The School of Lost Arts as part of 'Moving Out of Doors.' We followed in the footsteps of women from Victorian suffrage groups who went door-to-door in these streets and those across Victoria in 1891 collecting signatures for what became known as the 'Monster Petition' presented to Parliament to demand the right to vote for Victorian women. Photo credit: Photo: (c) Dee Heddon and Misha Myers, Walking Library for a Walking Women, 2017, Performance. Page design: Misha Myers. 


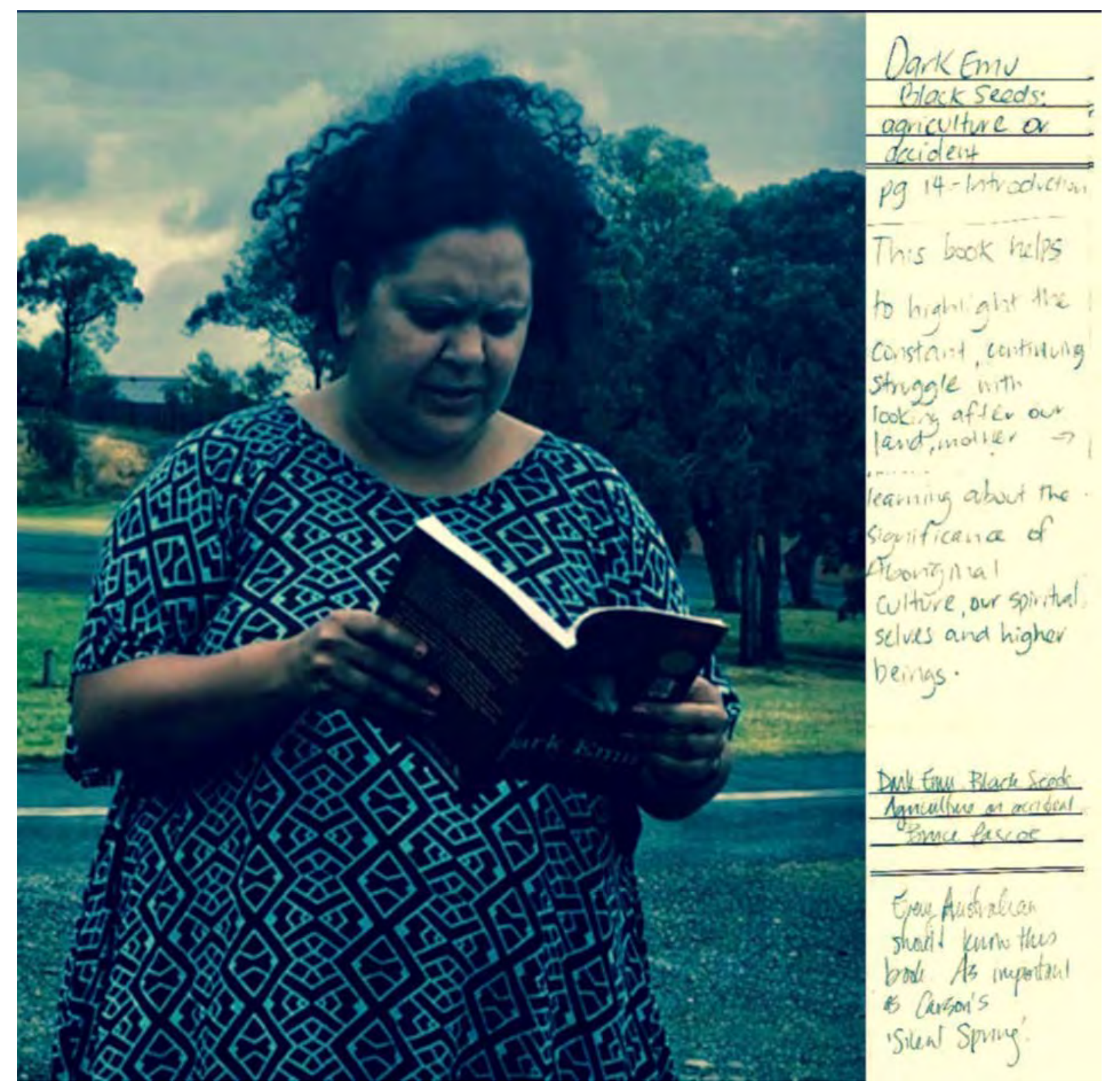

Figure 6: Image of a participant sharing a reading from Black Emu, the book she carried on the Walking Library for Women Walking walk in Geelong (Australia), 16 November 2017. Photo credit: Photo: (c) Dee Heddon and Misha Myers, Walking Library for a Walking Women, 2017, Performance. Page design: Misha Myers. 


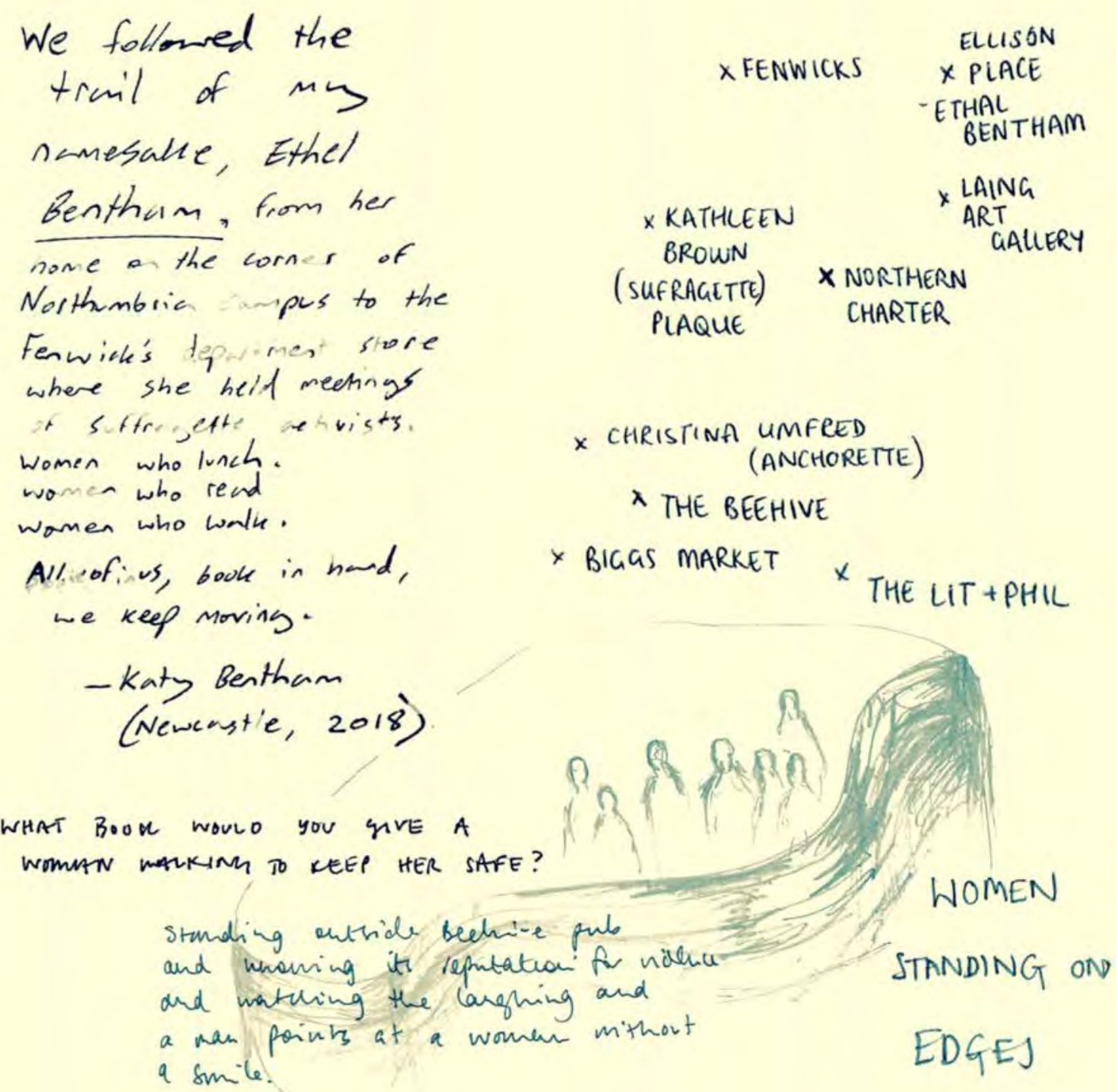

Figure 7: Composite of response cards from The Walking Library for Women Walking, Newcastle (UK), 27 January 2018, in partnership with the Women Artists of the North East Library. This walk followed in the footsteps of significant women from Newcastle's history. Photo credit: Page design: Misha Myers. 


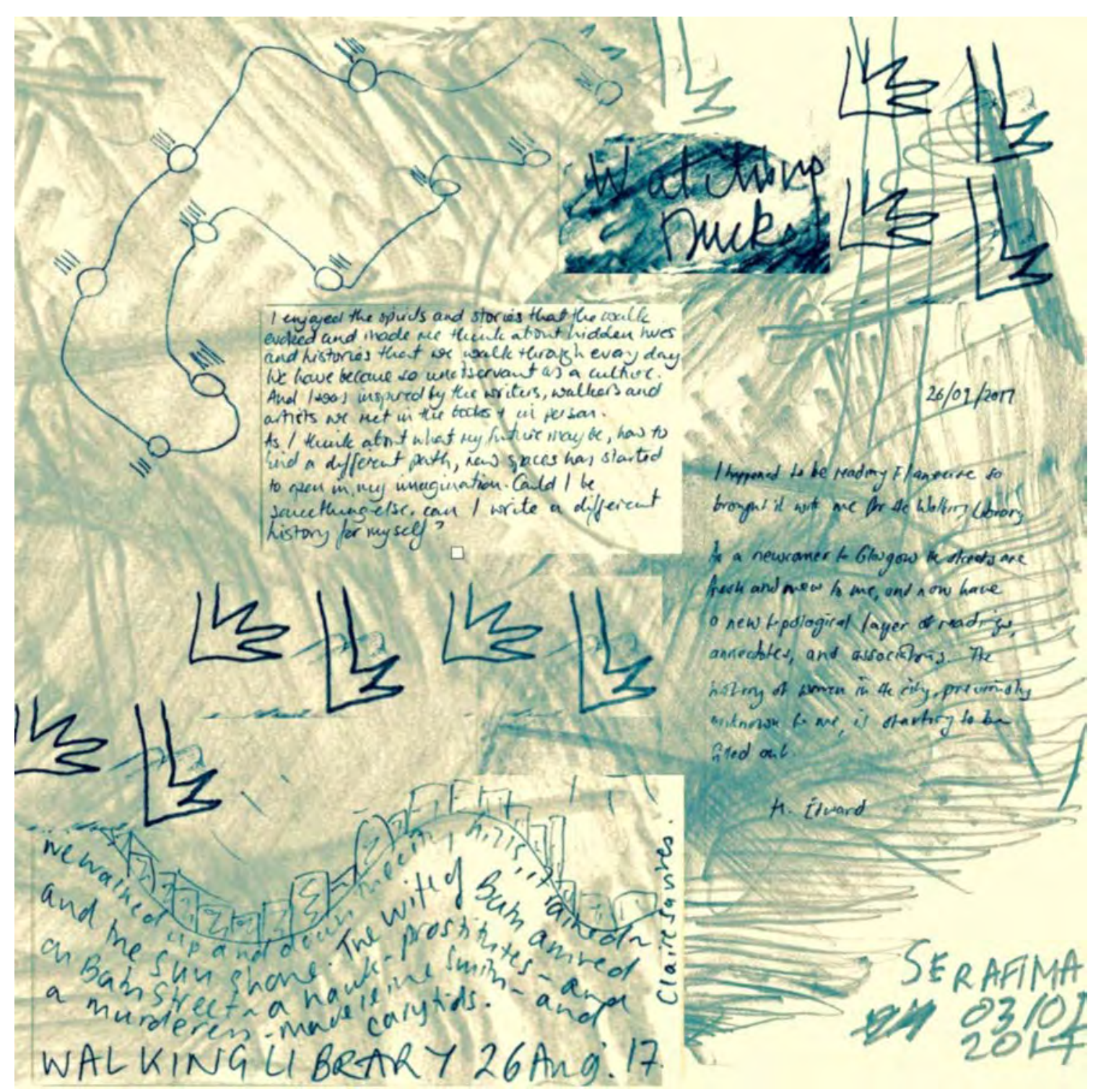

Figure 8: Composite of participant response cards from various Walking Library for Women Walking walks taken in Edinburgh and Glasgow on 3 February 2017, 26 August 2017 and 26 September 2017. The responses reflect common threads held between the WLFWW walks: how walking and reading together inscribes women into place and history. Photo credit: Page design: Misha Myers. 


\section{References}

Heddon, D., \& Myers, M. (2014). Stories from the walking library. Cultural Geographies, 21(4), pp. 639-55. https://doi.org/10.1177/1474474014521361

Heddon, D., \& Myers, M. (2017). The walking library: Mobilising books, places, readers and reading. Performance Research, 22(1), pp. 32-48.

https://doi.org/10.1080/13528165.2017.1285560

Heddon, D., \& Myers M. (in press). The walking library for women walking. In D.

Borthwick, P. Marland \& A. Stenning, (Eds.), Walking: Landscape and Environment. London, UK: Routledge.

McCusker, G. (2017). A feminist teacher's account of her attempts to achieve the goals of feminist pedagogy. Gender and Education, 29(4), pp. 445-460. https://doi.org/10.1080/09540253.2017.1290220

Osberg, D., Biesta, G., \& Cilliers, P. (2008). From representation to emergence: Complexity's challenge to the epistemology of schooling. Educational Philosophy and Theory, 40(1), pp. 213-227. https://doi.org/10.1111/j.1469-5812.2007.00407.x

Dee Heddon holds the James Arnott Chair in Drama at the University of Glasgow. She has written extensively on autobiography, devising, and walking in performance. She has collaborated with Misha Myers on The Walking Library since 2012. She is currently writing a monograph called Performing Forests.

Misha Myers is Course Director of Creative Arts at Deakin University. She has written about and created works that use mobile, location-based and interactive methods and technologies of storytelling and performance.

Since founding The Walking Library in 2012, Heddon and Myers have made a number of editions including The Walking Library for Sideways Festival and The Walking Library for Women Walking. Each edition starts with a specific question, which becomes the prompt for a new collection of recommended and donated books. The Walking Library functions as a mobile laboratory to explore relationships between walking, books and place. https://walkinglibraryproject.wordpress.com/ 